\title{
Do you know how I feel? Evaluating emotional display of primary and secondary emotions
}

\author{
Julia Tolksdorf, Christian Becker-Asano, Stefan Kopp \\ Artificial Intelligence Group, University of Bielefeld, 33594 Bielefeld, Germany \\ \{jtolksdo, cbecker, skopp\}@techfak. uni-bielefeld.de
}

\section{Motivation and Description of Study}

In this paper we report on an empirical study on how well different facial expressions of primary and secondary emotions [2] can be recognized from the face of our emotional virtual human Max [1]. Primary emotions like happiness are more primitive, onto-genetically earlier types of emotions, which are expressed by direct mapping on basic emotion display; secondary emotions like relief or gloating are considered cognitively more elaborated emotions and require a more subtle rendition. In order to validate the design of our virtual agent, which entails devising facial expressions for both kinds of emotion, we tried to find answers to the questions: How well can emotions be read from a virtual agent's face by human observers? Are there differences in the recognizability between more primitve primary and more cognitively elaborated secondary emotions?

In our study, facial expressions of six primary emotions (see Table 1(a)) and seven secondary emotions (see Table 1), i.e. 13 in total, had to be rated on a questionnaire. Stimuli expressions of the secondary emotions were created from pictures and movie actors, as no sufficiently precise specifications was available. Each subject saw a sequence of 15 still pictures of Max's face and had to rate each face for its emotional content by choosing from a total of 15 candidate emotion labels, which were illustrated by an additional German example sentence and could further be weighted by choosing either "maybe", "pretty similar", or "almost perfect". Choosing a weighted second emotion term was optionally possible as well. The order of stimuli was randomized across subjects. Prior to the study it was made clear that there is no correct choice, but that we were only interested in each subject's subjective opinion. Participants' age ranged from 18 to 66 (mean value 31.7 years), $67 \%$ were male, $33 \%$ female, and $28 \%$ had prior experiences with our Virtual Human Max.

\section{Results and Discussion}

The study provided a total of 100 complete data sets. First, we analyzed which emotion label was assigned to which picture and found that the following stimuli were most recognizable: ashamed, happy, concentrated, surprised, sad, and angry. For frustrated, bored, annoyed, relieved, hopeful, jealous, proud, and gloat 
Table 1. The presented primary and secondary emotions (with translations); labels in italics indicate a correspondence to one of Ekman's basic emotions [3]

(a) Primary emotions

\begin{tabular}{|l|l|l|}
\hline english & german & facial expr. \\
\hline happy & erfreut & happiness \\
bored & gelangweilt & bored \\
concentrated & konzentriert & neutral \\
annoyed & genervt & sadness \\
sad & traurig & sadness \\
surprised & überrascht & surprise \\
angry & wütend & anger \\
\hline
\end{tabular}

(b) Secondary emotions

\begin{tabular}{|l|l|}
\hline english & german \\
\hline gloating & schadenfroh \\
ashamed & beschämt \\
relieved & erleichtert \\
jealous & neidisch \\
proud & stolz \\
frustrated & frustriert \\
hopeful & hoffnungsvoll \\
\hline
\end{tabular}

this does not apply. A correlation analysis revealed a significant relationship between the presented picture and the participant's choice $\left(\chi^{2}=7087.856\right.$; $\mathrm{df}=$ $546 ; \mathrm{p}<0.001)$. The majority of primary emotions were recognized as expected, with the pictures sad and annoyed correlating with the label angry. Among the secondary emotions, the expressions of gloat, ashamed, relieved, and proud were recognized quite well, in contrast to jealous, frustrated, and hopeful. In total, the labels for the primary emotions happy and sad were chosen very often, while labels for the secondary emotions jealous, proud, and gloat were rarely selected.

We then tested for a correlation between the labels and the pictures they were assigned to. A $\chi^{2}$ analysis revealed a significant relationship $\left(\chi^{2}=3715.888\right.$; df $=210 ; \mathrm{p}<0.001)$ meaning that the most significant amount of choices was given to the "correct" stimulus. The label happy was distributed over a high number different stimuli that showed positive facial expressions (e.g. the secondary emotion hopeful). It turned out that each positive stimulus presented first very often got the label happy. Thereafter, participants tended to choose the label happy less often in the following pictures. The label sad, on the contrary, had a high amount of votes and was mostly assigned to the "correct" picture.

Overall, primary emotions seem to be better recognizable than secondary ones. Moreover, the facial expressions, which are based on four "basic emotions" to express primary emotions, are not only much better recognizable but also chosen more frequently than emotion terms denoting secondary emotions. This supports our assumption that secondary emotions, such as relief or hope, cannot be revealed by facial expressions alone.

\section{References}

1. C. Becker, S. Kopp, and I. Wachsmuth. Why emotions should be integrated into conversational agents. In T. Nishida, editor, Conversational Informatics: An Engineering Approach, chapter 3, pages 49-68. Wiley, November 2007.

2. A. Damasio. Descartes' Error, Emotion Reason and the Human Brain. Grosset/Putnam, 1994.

3. P. Ekman. Facial expressions. In Handbook of Cognition and Emotion, chapter 16, pages 301-320. John Wiley \& Sons, 1999. 